Review

\title{
Development of headspace solid-phase microextraction-gas chromatography-mass spectrometry methodology for analysis of terpenoids in Madeira wines
}

\author{
J.S. Câmara ${ }^{\mathrm{a}, *}$, M. Arminda Alves ${ }^{\mathrm{b}}$, J.C. Marques ${ }^{\mathrm{a}}$ \\ a Depto. de Química da Universidade da Madeira, Campus Universitário da Penteada, 9000-390 Funchal, Madeira, Portugal \\ b Depto. de Eng Química, Faculdade de Engenharia, Universidade do Porto, Rua Dr. Roberto Frias, 4200-465 Porto, Portugal \\ Received 17 February 2005; received in revised form 1 September 2005; accepted 5 September 2005
}

Available online 3 October 2005

\begin{abstract}
A dynamic headspace solid-phase microextraction methodology was developed for analysis of varietal aroma compounds in must and Madeira wine samples, a spirit wine with an ethanol content of $18 \%(\mathrm{v} / \mathrm{v})$. The factors with influence in the headspace solid-phase microextraction efficiency such as: fibre coating, extraction time and temperature, $\mathrm{pH}$, ionic strength, ethanol content, desorption time and temperature, were optimised and the method validated. The best results were obtained for a $85 \mu \mathrm{m}$ polyacrylate fibre, with a 60 min headspace for must and 120 min for wine samples, in a $2.4 \mathrm{ml}$ sample at $40^{\circ} \mathrm{C}$ with $30 \%$ of $\mathrm{NaCl}$. The extract is injected in the splitless mode in a GC-MS Varian system, Saturn III, and separated on a Stabilwax capillary column. The linear dynamic range of the method covers the normal range of occurrence of analytes in wine with typical $r^{2}$ between 0.985 ( $\beta$-ionone) and 0.998 (linalool) for musts and between 0.980 ( $\alpha$-terpineol) and 0.999 (linalool) for must and wine samples, respectively. For must samples the reproducibility ranges from $2.5 \%$ (citronellol) to $14.4 \%$ (nerolidol) (as R.S.D.), and from $4.8 \%$ (citronellol) to $14.2 \%$ (nerolidol) for wine samples. The analysis of spiked samples has shown that matrix effects do not significantly affect method performance. Limits of detection obtained are in low $\mu \mathrm{gl}^{-1}$ range for all compounds analysed in this study.
\end{abstract}

(C) 2005 Elsevier B.V. All rights reserved.

Keywords: Solid-phase microextraction; Optimisation; Varietal compounds; Must; Wine

\section{Contents}

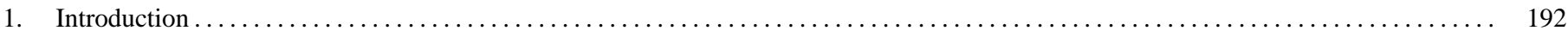

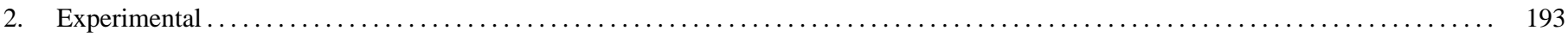

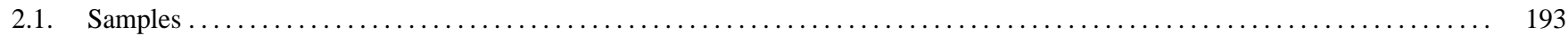

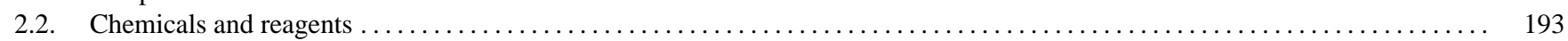

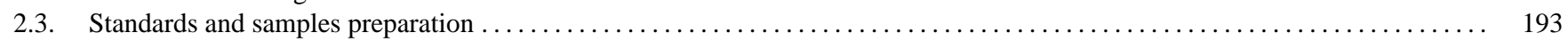

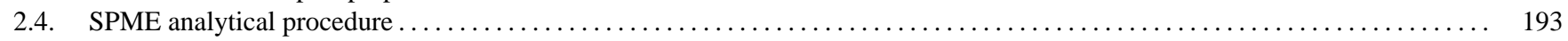

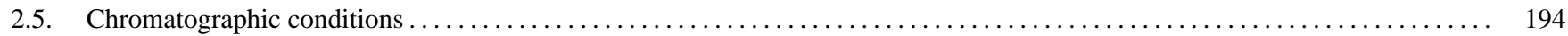

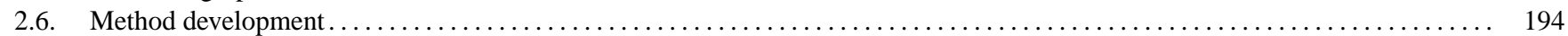

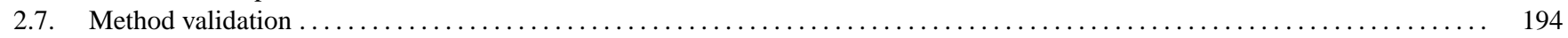

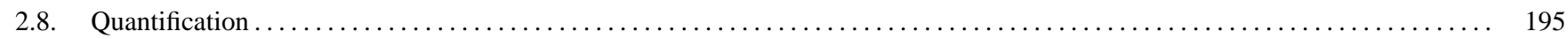

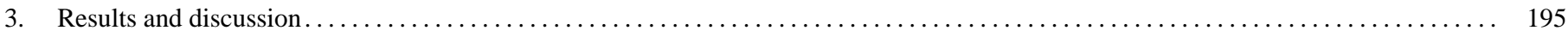

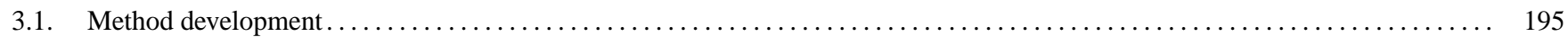

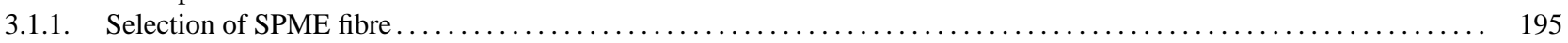

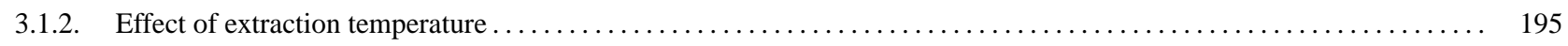

\footnotetext{
* Corresponding author. Tel.: +351291 705100/2; fax: +351 2917051449 .

E-mail address: jsc@uma.pt (J.S. Câmara).
} 


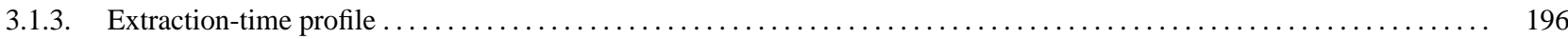

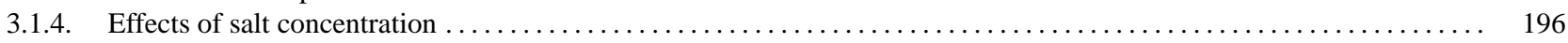

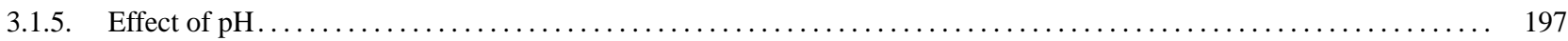

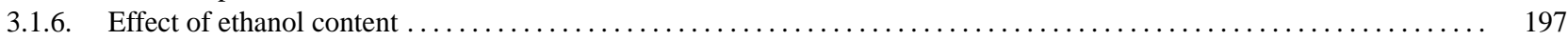

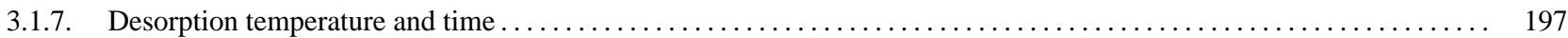

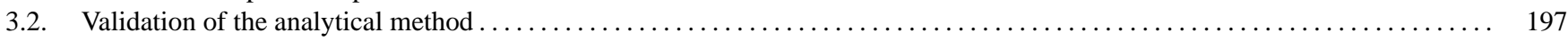

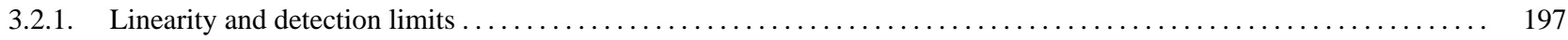

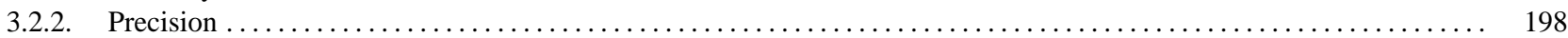

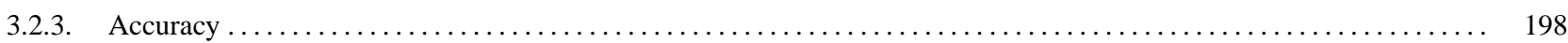

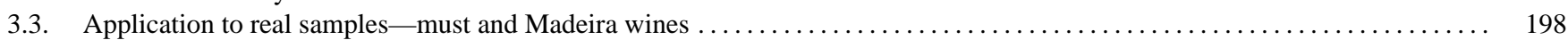

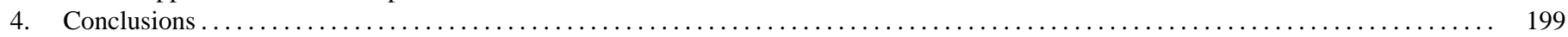

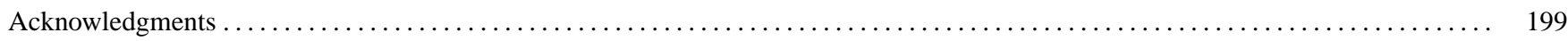

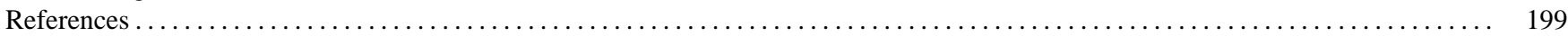

\section{Introduction}

Since the 16th century, the Portuguese Madeira Island produced one of the most famous wines known over the world as Madeira wine. These can be characterised by a typical vinification and aging procedure that includes fortification (addition of natural grape spirit), in order to obtain an alcoholic content between 18 and $22 \%(\mathrm{v} / \mathrm{v})$, followed by a baking process known as "estufagem", during which the wine is submitted to rather high temperatures $\left(45-50{ }^{\circ} \mathrm{C}\right)$ for 3 months. The physicochemical and organoleptic characteristics of such fortified wines depend on several factors concerning the specific area of production, climate, nature of soil, grape varieties, the degree of ripeness, fermentation conditions, wine making processes and aging of the wine [1].

The volatile fraction of a wine can be composed of more than 800 different compounds [2,3] but only 30-40 of which can be odour-active [4,5]. A key position is held by monoterpenols especially for the aroma of Muscat and related cultivars, but also could contribute to the aroma of other non-Muscat cultivars such as Boal, Malvazia, Sercial and Verdelho from which Madeira wines are made. These varieties are perfectly adapted to the sandy soil as well as to the climatic conditions that characterise the region where are cultivated.

Some components are present in high concentration (hundreds of $\mathrm{mgl}^{-1}$ ), but most are found at the low $\mathrm{ng}^{-1}$ level. Therefore some components need to be extracted and concentrated before analysis, while others can be analysed by GC with direct injection. However, the major compounds from the complex wine matrix cause some interference and make analysis of trace compounds problematic. Since the majority of the terpenoid compounds occur in micro concentrations (in grapes, must and wines) their quantification is quite difficult.

Several classical analytical methods such as liquid-liquid extraction (LLE) [6-8], liquid-liquid microextraction (LLME) $[7,9,10]$, simultaneous distillation-solvent extraction [11], solidphase extraction (SPE) [12-16], supercritical fluid extraction [17], microwaves extraction [18] and ultrasound extraction [19], among others, have been developed for the analysis of the minor volatile compounds in wines. These classical analytical methods have some drawbacks such as the relatively low reproducibility, possibility of contamination with solvents, the length of time required and insufficient selectivity. SPE and LLME are rapid and inexpensive, but to achieve the required limits of detection, a concentration step (solvent evaporation) is required, which increases the sample preparation step and may also cause loss of volatile analytes during the evaporation.

In the beginning of 90 decade, a new variation of adsorption technique called solid-phase microextraction (SPME) has been developed by Pawliszyn and co-workers [20-22]. Compared to traditional techniques this new technique offers many advantages such as high sensitivity and reproducibility, does not require solvent and combines extraction and pre-concentration in a single step without pre-treatment of samples. Moreover it is fast, inexpensive, requires low sample volumes and can be easily automated [23-26]. This technique has been successfully been used in wine samples [27-29] to characterise a wide range of aroma compounds, including monoterpenes and $\mathrm{C}_{13}$ norisoprenoids [30], esters [31], volatile and low volatile sulphides and disulphides [32-34], oak lactones in barrel aged wines [35], organochlorine insecticides in Portuguese red and white wines [36] and 3-alkyl-2-methoxypyrazines in CabernetSauvignon and Merlot wines [37]. SPME has also been applied for the analysis of Portuguese muscatel wines [38], for the classification of Nebbiolo-based wines from Piedmont [39] and for varietal characterisation of Madeira wines [30]. More recently was reported the application of SPME to the characterisation of varietal wines, using PDMS as stationary phase [40]. The determination of esters [31] and major compounds in dry and sweet wines [41] were also performed by HS-SPME in commercial wines from the Canary Islands.

In HS-SPME analyses, a fibre is placed in the headspace above an equilibrated sample. Two types of equilibrations take place: $K_{\text {sample-air }}$ and $K_{\text {air-fibre. }}$ The amount of the flavour compounds absorbed on the SPME coating can be determined from the equation $n=C_{0} V_{1} V_{2} K_{\text {air-fibre }} K_{\text {sample-air }} /$ ( $K_{\text {air-fibre }} K_{\text {sample-air }} V_{1}+K_{\text {sample-air }} V_{3}+V_{2}$ ). $n$ is the mass of the flavour compound absorbed by the SPME coating. $C_{0}$ is the initial concentration of the flavour compound in the sample, and $V_{1}, V_{2}$ and $V_{3}$ are the volumes of SPME coating, sample volume and the headspace volume, respectively. $K_{\text {air-fibre }}$ is the partition coefficient of the flavour compounds between the SPME coating and the headspace; $K_{\text {sample-air }}$ is the headspace and the sample partition coefficient The PDMS and PA fibres 
extract analytes via absorption [42]. The remaining coatings, including PDMS-DVB, Carbowax-DVB, and Carboxen are mixed coatings, in which the primary extracting phase is a porous solid, extracting analytes via adsorption. Independently of the nature of the coating, analyte molecules initially get attached to its surface. Whether they migrate to the bulk of the coating or remain at its surface depends on the magnitude of the diffusion coefficient of an analyte in the coating.

Weak intermolecular interactions play the most important role in analyte extraction by the porous polymer SPME coating. The number of surface sites where adsorption can take place is limited. So, when all sites are occupied no more analyte can be trapped $[43,44]$. This means that the dependence between the concentration of the analyte in a sample and the amount of the analyte extracted by SPME coating cannot be linear over broad concentrations ranges. Moreover, while absorption is a noncompetitive process, adsorption is competitive, and a molecule with higher affinity for the surface can replace a molecule with lower affinity. Thus the amount extracted by the fibre can be significantly affected by sample matrix composition.

SPME is very sensitive to experimental conditions. Any changes of experimental parameters, which affect the distribution coefficient and absorption rate, will also influence the amount absorbed on the SPME fibre and the corresponding reproducibility.

The purpose of this study was to develop and optimise an HS-SPME procedure for the determination of trace levels of terpenoid compounds-linalool, $\alpha$-terpineol, citronellol, nerol, geraniol, nerylacetone, nerolidol, $\beta$-damascenone, $\alpha$-ionone and $\beta$-ionone, in must and Madeira wine samples, a liquorous wine with a alcoholic content of $18 \%(\mathrm{v} / \mathrm{v})$. The method is based on the extraction of the analytes of the interest from headspace over the must and wine samples with SPME, followed by GC-MS analysis. The factors affecting the SPME process extraction such as fibre coating, extraction time and temperature, $\mathrm{pH}$, ionic strength, ethanol content, desorption time and temperature, were studied.

\section{Experimental}

\subsection{Samples}

Must and wine samples from Boal, Malvazia, Sercial and Verdelho varieties of 2000 vintage were supplied from Instituto do Vinho Madeira (IVM) and Madeira Wine Company (MWC). The vinification process for all varieties was carried out at the same way. The fermentation is stopped by addition of spirit when the appropriate amount of natural grape sugars, according to the wine type to obtain (sweet, medium sweet, dry and medium dry), has been fermented. The 36 wine samples were collected 8 months after fermentation and stored at $-28^{\circ} \mathrm{C}$ until use.

\subsection{Chemicals and reagents}

The standards of the different terpenoid compounds studied: linalol (lin), $\alpha$-terpineol (ter), citronellol (cit), nerol (ner), geraniol (ger), nerylacetone (neril), nerolidol (nero), $\alpha$-ionone (a-ion) and $\beta$-ionone (b-ion), with a purity above $98 \%$, were supplied by Sigma-Aldrich (Portugal) and used without previous purification step. $\beta$-Damascenone (dam) was purchase by Firmenich (Switzerland). Octan-3-ol (99.8\%) purchased by Sigma-Aldrich was used as internal standard (IS).

Methanol and ethanol HPLC grade (purity $<99.8 \%$ ), were provided by Merck (Darmstadt, Germany). Sodium chloride $(\mathrm{NaCl})$ of analytical grade (Merck, Darmstadt, Germany), used in the ionic strength adjust was previously heated at $500{ }^{\circ} \mathrm{C}$ for $9 \mathrm{~h}$. Water (HPLC grade) was obtained from a Milli-Q system (Millipore).

\subsection{Standards and samples preparation}

Individual stock standard solutions of each terpenoid compound were prepared by weight in methanol and stored until use. The internal standard (IS) solution was done in hydro alcoholic solution $(1 / 1, \mathrm{v} / \mathrm{v})$. Working solution used in further studies containing the following compounds at fixed concentrations: linalool (lin), $429.5 \mu \mathrm{gl}^{-1}$; $\alpha$-terpineol (ter), $112.8 \mu \mathrm{gl}^{-1}$; citronellol (cit), $57.6 \mu \mathrm{gl}^{-1}$; nerol (ner), $43.8 \mu \mathrm{gl}^{-1}$; geraniol (ger), $43.9 \mu \mathrm{gl}^{-1}$; nerylcetone (neril), $86.8 \mu \mathrm{gl}^{-1}$; nerolidol (nero), $43.8 \mu \mathrm{gl}^{-1} ; \beta$-damascenone (dam), $93.4 \mu \mathrm{gl}^{-1} ; \alpha$ ionone (a-ion), 77.6 $\mu \mathrm{gl}^{-1}$; and $\beta$-ionone (b-ion), 77. $\mu \mathrm{gl}^{-1}$, were prepared by diluting different amounts of the global standard solution in a synthetic matrix with ethanol content at $18 \%$ (v/v) and $\mathrm{pH}$ at 3.3.

Finally five calibration solutions $(18 \%, \mathrm{v} / \mathrm{v})$ in the range specified in Table 1 were prepared by suitable dilution of the global solution and tested in triplicate; these concentrations covered the concentration ranges expected for terpenoids in must and Madeira wine samples studied. The concentration of internal standard in all calibration solutions was $0.422 \mu \mathrm{g} \mathrm{l}^{-1}$.

To $10 \mathrm{ml}$ of centrifuged $(5000 \mathrm{rpm})$ must and wine samples were added $3 \mathrm{~g}$ of $\mathrm{NaCl}$ and $10 \mu \mathrm{l}$ of octan-3-ol in hydro alcoholic solution $(1 / 1, \mathrm{v} / \mathrm{v})$ at $422 \mathrm{mg}^{-1}$ as internal standard. The solution was stirred during $5 \mathrm{~min}$ at $1250 \mathrm{rpm}$.

\subsection{SPME analytical procedure}

The SPME fibres (PDMS, PDMS/DVB, Car/PDMS and PA $85 \mu \mathrm{m})$ and the SPME holder for manual sampling used in this study were purchased from Supelco (Bellefonte, PA, USA). The fibres were conditioned prior to use according to the manufacturer's instructions by inserting them into the GC injector port. Before the first daily analysis the fibres were conditioned for $5 \mathrm{~min}$ at $260^{\circ} \mathrm{C}$. A blank test was performed to check possible carry-over.

Standard solutions, must and wine samples were adjusted to $\mathrm{pH} 3.3$ and the ionic strength was increased to improve the extraction efficiency using $\mathrm{NaCl}(30 \%)$. A $4 \mathrm{ml}$ vial containing $2.4 \mathrm{ml}$ of sample (standard, must or wine) was placed in a thermostatic block on a stirrer. The fibre was then exposed to the gaseous phase during the sampling time period (Fig. 4) at temperature of $40 \pm 1{ }^{\circ} \mathrm{C}$. As stirring usually improves the extraction, because the static layer resistant to mass transfer is destroyed, all the experiments were performed under con- 
Table 1

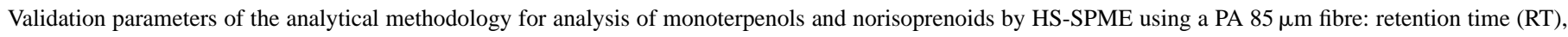

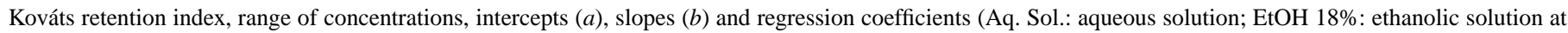
$18 \%(\mathrm{v} / \mathrm{v}))$

\begin{tabular}{|c|c|c|c|c|c|c|c|c|}
\hline \multirow[t]{2}{*}{ Peak no. } & \multirow[t]{2}{*}{ Compound } & \multirow[t]{2}{*}{ RT (min) } & \multirow{2}{*}{$\begin{array}{l}\text { Kováts retention } \\
\text { index }\end{array}$} & \multirow{2}{*}{$\begin{array}{l}\text { Range of concentrations } \\
\left(\mu g 1^{-1}\right)\end{array}$} & \multirow[t]{2}{*}{$a$} & \multirow[t]{2}{*}{$b$} & \multicolumn{2}{|l|}{$r^{2}$} \\
\hline & & & & & & & Aq. Sol. & $\mathrm{EtOH} 18 \%$ \\
\hline 1 & Linalol & 46.63 & 1555 & $4.4-68.7$ & -0.0026 & 0.1562 & 0.999 & 0.998 \\
\hline 2 & $\alpha$-Terpineol & 61.29 & 1704 & $3.0-18.1$ & 0.2014 & 0.4111 & 0.980 & 0.996 \\
\hline 3 & Citronellol & 69.66 & 1785 & $0.3-19.2$ & 0.0095 & 0.4049 & 0.996 & 0.995 \\
\hline 4 & Nerol & 72.05 & 1819 & $1.5-14.9$ & 0.0087 & 0.2859 & 0.996 & 0.994 \\
\hline 5 & $\beta$-Damascenone & 72.60 & 1830 & $1.4-10.5$ & 0.0105 & 0.7678 & 0.991 & 0.996 \\
\hline 6 & Nerylacetone & 74.93 & 1865 & $0.9-20.8$ & 0.0102 & 0.4184 & 0.994 & 0.995 \\
\hline 7 & $\alpha$-Ionone & 75.66 & 1868 & $0.8-12.4$ & 0.0046 & 0.9139 & 0.999 & 0.996 \\
\hline 8 & Geraniol & 77.98 & 1871 & $1.4-17.0$ & 0.0052 & 0.4211 & 0.997 & 0.988 \\
\hline 9 & $\beta$-Ionone & 84.32 & 1936 & $1.9-15.1$ & 0.0142 & 1.1298 & 0.996 & 0.985 \\
\hline 10 & Nerolidol & 92.15 & 2205 & $2.4-20.5$ & 0.0747 & 0.3500 & 0.977 & 0.992 \\
\hline
\end{tabular}

stant stirring velocity $(1250 \mathrm{rpm})$. After extraction, the SPME fibre was withdrawn into the needle, removed from the vial and inserted into the hot injector port $\left(260^{\circ} \mathrm{C}\right)$ of the GC-MS system where the extracted chemicals were desorbed thermally and transferred directly to the analytical column.

The SPME extraction yield was determined as the ratio between the extracted amount (calculated from calibration curves of standards) and the initial concentration of the standards. All standards and samples were analysed in triplicate.

\subsection{Chromatographic conditions}

The must and wine extracts were analysed by GC-MS using a Varian STAR 3400Cx series II gas chromatograph, equipped with a $30 \mathrm{~m} \times 0.25 \mathrm{~mm}$ i.d., with a $0.25 \mu \mathrm{m}$ film thickness, Stabilwax fused silica capillary column, connected to a Varian Saturn III mass selective detector, according to the method described by Câmara et al. [45]. Splitless injections were used. The initial oven temperature was set to $40^{\circ} \mathrm{C}$ for $1 \mathrm{~min}$. The temperature was increased in three steps: $40-120^{\circ} \mathrm{C}$ at $1^{\circ} \mathrm{min}^{-1}$; $120-180^{\circ} \mathrm{C}$ at $1.7^{\circ} \mathrm{min}^{-1}$ and $180-220^{\circ} \mathrm{C}$ at $25^{\circ} \mathrm{min}^{-1}$. Each step was preceded by a small period at constant temperature of 2, 1 and $10 \mathrm{~min}$, respectively. The injector temperature was $250{ }^{\circ} \mathrm{C}$ and the transfer line was held at $220^{\circ} \mathrm{C}$. The detection was performed by a Saturn III mass spectrometer in the EI mode (ionisation energy, $70 \mathrm{eV}$; source temperature, $180^{\circ} \mathrm{C}$ ). The acquisition was made in scanning mode (mass range 30-300 $\mathrm{m} / z ; 1.9 \mathrm{spectra} / \mathrm{s}$ ). A solvent delay time of $3 \mathrm{~min}$ was used to avoid overloading the mass spectrometer with ethanol. For identification of the wine flavour compounds a solution of $n$-alkanes (n-octane- $n$-hexadecane) was injected in the GC-MS system after desorption of an SPME extract of wine, and the analysis was performed using the same instrumental conditions. This allows calculate the Kováts retention indexes for each compound and compare with the literature in order to ensure the correct identification of the compounds (Table 1). Comparison with retention times and mass spectra obtained from the sample with those from the pure standards injected under the same conditions were also used (Fig. 1).

\subsection{Method development}

In order to optimise the analytical method developed, several SPME factors influencing the equilibrium: fibre coating, extraction time and temperature, $\mathrm{pH}$, ionic strength, ethanol content, desorption time and temperature, were previously studied before validating the analytical methodology. Experiments were carried out with aqueous solutions and hydro alcoholic solution (18\%, $\mathrm{v} / \mathrm{v})$ buffered at $\mathrm{pH} 3.3$ with tartaric acid $\left(5 \mathrm{gl}^{-1}\right)$ and spiked with a known amount of each compound (three times diluted than global solution). Octan-3-ol was used as internal standard at a concentration level of $0.422 \mu \mathrm{g} \mathrm{l^{-1 }}$. After select the better conditions for HS-SPME analysis the method was validated by studying the range of linearity, limits of detection and quantification and accuracy. The analyses of variance (ANOVA) was used for evaluate the occurrence of statistically significant differences.

\subsection{Method validation}

Synthetic solutions containing known amounts of terpenoid compounds were extracted and analysed by the proposed procedure. The range of concentrations of compounds studied is given in Table 1. The HS-SPME extraction was performed in triplicate. The relative area was plotted against the relative concentration. The linear model is adjusted by the least-squares method.

The repeatability is determined by six replicates analysis of the wines by the proposed method. For each assay the average values and the relative standard deviation (R.S.D.) were calculated. To evaluate the recovery percent of the analytical methodology, a wine sample fortified with known amounts of the terpenoid compounds (two levels) were extracted and analysed by the proposed procedure.

The limits of detection (LOD) were estimated as the concentration of the analyte that produce a signal-to-noise ratio of 3 , that is $3 s_{y / x} / b$, where $s_{y / x}$ is the blank standard deviation and $b$ is the slope of the line regression. The linear range experiments provide the necessary information to calculate the limits of detection, by extrapolating from the lowest concentration point 


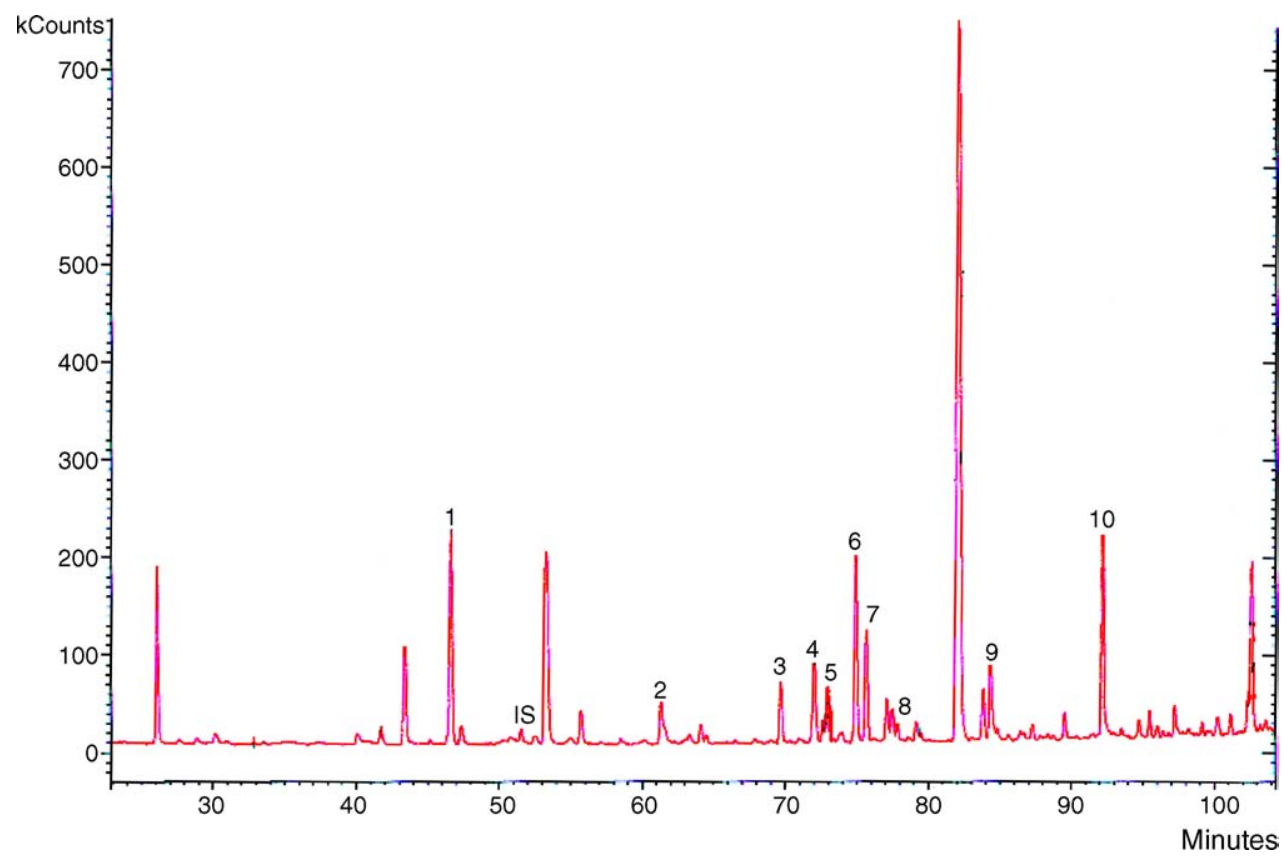

Fig. 1. Total ion chromatogram of a standard ethanolic solution at $18 \%(\mathrm{v} / \mathrm{v})$ of monoterpenols and $\mathrm{C}_{13}$ norisoprenoids extracted using a PA $85 \mu \mathrm{m}$ fibre in the dynamic headspace sampling mode. The sample volume was $2.4 \mathrm{ml}$ (vial $4 \mathrm{ml}$ ) containing $30 \%$ of $\mathrm{NaCl}$. The SPME sampling time: 120 min; sampling temperature: $40^{\circ} \mathrm{C}$; desorption temperature: $260^{\circ} \mathrm{C}$; desorption time: $5 \mathrm{~min}$ (for peak identification see Table 1 ).

on the linear calibration curve. The limit of quantification (LOQ) can also be estimated as the concentration of analyte producing a signal 10 times that of the noise.

\subsection{Quantification}

For quantification of terpenoid compounds "synthetic wines" containing known amounts of these compounds, were extracted and analysed by the proposed procedure. The results were used for the construction of calibration graphs. However, considering the effect of ethanol content in the extraction yield, for terpenoid must samples quantification were used calibration graphs with the standards in aqueous solution $(\mathrm{pH} 3.3 ; 30 \% \mathrm{NaCl})$ and for terpenoid wine samples quantification were used calibration graphs with the standards in hydro alcoholic solution $(18 \%, \mathrm{v} / \mathrm{v} ; \mathrm{pH} 3.3$; $30 \% \mathrm{NaCl}$ ).

\section{Results and discussion}

\subsection{Method development}

\subsubsection{Selection of SPME fibre}

Four commercially available SPME fibres differing in the solvent phase coating were tested and compared in this study to determine which fibre most effectively extracted the terpenoid compounds [100 $\mu \mathrm{m}$ poly(dimethylsiloxane) (PDMS), $65 \mu \mathrm{m}$ poly(dimethylsiloxane)-divinylbenzene (PDMS/DVB), $75 \mu \mathrm{m}$ carboxene-poly(dimethylsiloxane) (Car/PDMS) and $85 \mu \mathrm{m}$ poly(acrylate) (PA $85 \mu \mathrm{m})]$. The results of the fibre comparison study are shown in Fig. 2.

PDMS, PDMS-DVB and Car-PDMS fibres were inefficient for the most of the terpenoid compounds under study, which showed a relatively lower extraction efficiency than the PA $85 \mu \mathrm{m}$ coated fibre.

As shown in Fig. 2, the most suitable fibre for the extraction of the studied compounds was the PA $85 \mu \mathrm{m}$ coated fibre that extract all the analytes with good efficiency. Thus, the PA $85 \mu \mathrm{m}$ coated fibre was chosen for further optimisation and validation studies.

\subsubsection{Effect of extraction temperature}

In order to find the best temperature for extracting the terpenoid compounds, the effect of this parameter in the extraction of the analytes was checked. Fig. 3 reports the results obtained with three experiments with salt saturated standard solution of terpenoid compounds to compare the effect of three distinct temperature: 28,40 and $60^{\circ} \mathrm{C}$, in the extraction yield. The best results were obtained for an extraction temperature of $40^{\circ} \mathrm{C}$.

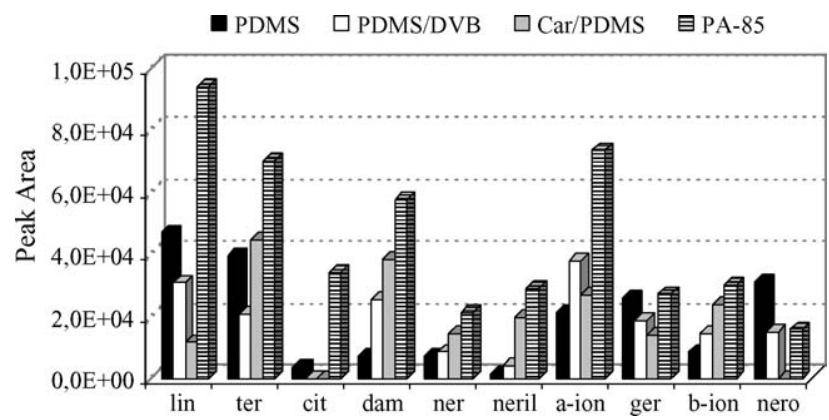

Fig. 2. Comparison of the extraction efficiency of terpenoid compounds in water solution by HS-SPME with different fibres. The sample volume was $2.4 \mathrm{ml}$ (vial $4 \mathrm{ml}$ ) containing $30 \%$ of $\mathrm{NaCl}$. The SPME sampling time: $60 \mathrm{~min}$; sampling temperature: $40^{\circ} \mathrm{C}$; desorption temperature: $260^{\circ} \mathrm{C}$; desorption time: 5 min (relative standard deviation range between $3.1 \%$ (linalool with PA fibre) and $13.4 \%$ (nerolidol with PDMS fibre)). 


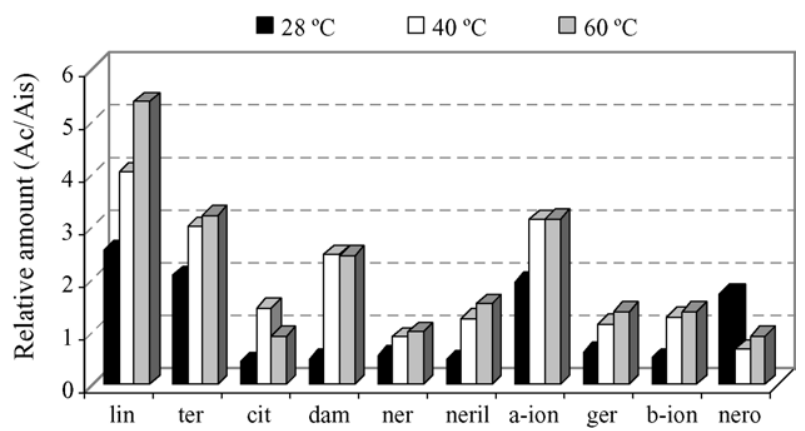

Fig. 3. Influence of temperature of extraction on the relative amount of the analytes studied. The sample volume was $2.4 \mathrm{ml}$ (vial $4 \mathrm{ml}$ ) containing $30 \%$ of $\mathrm{NaCl}$. The SPME sampling time: $60 \mathrm{~min}$; desorption temperature: $260^{\circ} \mathrm{C}$; desorption time: $5 \mathrm{~min}$ (Ac/Ais: ratio of compound area - Ac/area of internal standard - Ais) (relative standard deviation range between 2.8\% (linalool at $60^{\circ} \mathrm{C}$ ) and $10.8 \%$ (citronellol at $28^{\circ} \mathrm{C}$ ))

High temperatures could lead to the formation of artefacts caused by degradation. All the extractions were carried out in triplicate.

The temperature effect is not the same for all the compounds under study. High temperatures are supposed to release more analytes into the headspace, allowing better extraction during the increase with increasing temperature due to the enhanced mass transfer (kinetics). However they can adversely affect the absorption of analytes by the coating due the thermodynamic reasons (decrease of partition coefficients) and the extraction by the fibre coating decreases as the temperature rises.

\subsubsection{Extraction-time profile}

As the diffusion of the analytes through the three system phases is essential in HS-SPME technique, the effect of the time in the extraction of the analytes was optimised for aqueous and hydro alcoholic $(18 \%, \mathrm{v} / \mathrm{v})$ standard solution. The optimal time for extraction should be the time of equilibrium since the mechanism of SPME is based on the equilibrium between analyte and the polymeric phase of the fibre.

Different extraction times-from 5 to $360 \mathrm{~min}$, were examined and compared at optimum temperature $\left(40^{\circ} \mathrm{C}\right)$ using the PA $85 \mu \mathrm{m}$ fibres in the headspace-sampling mode. Fig. 4 shows the influence of the time in the extraction of terpenols by PA- $85 \mu \mathrm{m}$ fibre.

It is apparent that the extraction time profile depends on the individual analyte. Results showed that some compounds reached the equilibrium extraction between 30 and 40 min while others increase continuously in all the time considered. Although in principle it is desirable to continue extraction until equilibrium is achieved, in routine analysis there is often insufficient time to do so. Based on the curves from Fig. 4, and considering a compromise between the duration of the analysis and the time of the extraction, an extraction time of $60 \mathrm{~min}$ for must and $120 \mathrm{~min}$ for wine samples was selected for subsequent analysis, because this provides sufficient extraction (>80\%) of the analytes. After these time the extraction was not significantly improved.

\subsubsection{Effects of salt concentration}

The suitability of the headspace SPME technique for the extraction compounds depends on the transfer of the analyte
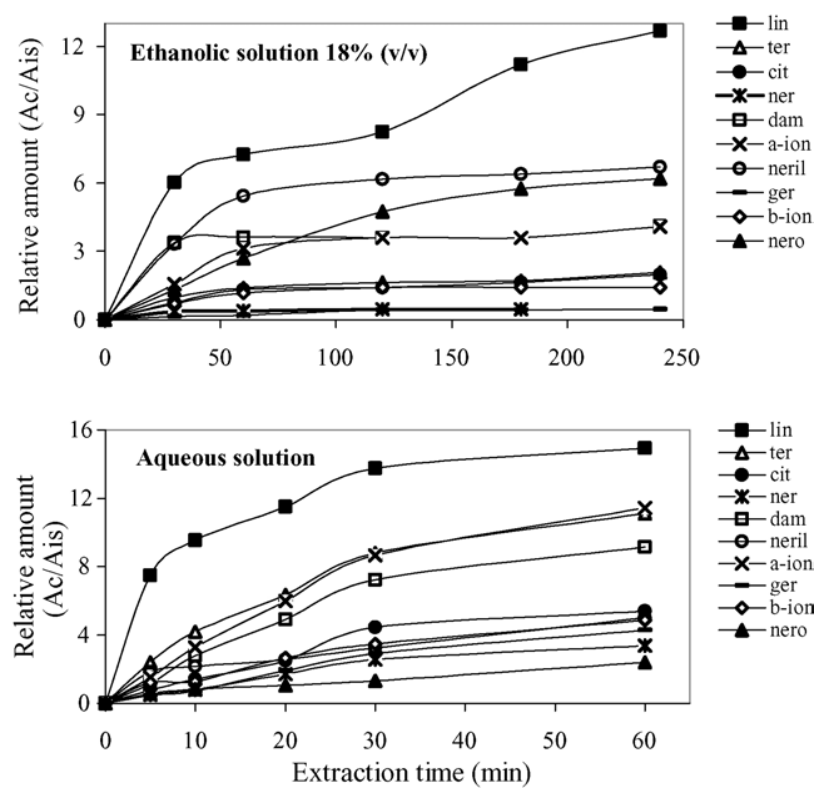

Fig. 4. Extraction time profiles for the compounds under study by dynamic headspace SPME using the PA $85 \mu \mathrm{m}$ fibre. The SPME sampling temperature: $40^{\circ} \mathrm{C}$; desorption temperature: $260^{\circ} \mathrm{C}$; desorption time: $5 \mathrm{~min}$.

from sample to the gaseous phase and therefore to the fibre. This process can be optimised by the increase of the ionic strength. Sodium chloride amounts of $0,10,20,30$ and $40 \%$ (w/v) were tested. Fig. 5 shows the salt effect on the HS-SPME absorption for the compounds investigated in these study.

The maximum extraction yields for individual terpenoid compounds were observed at different salt concentration. Primary it was observed that the chromatographic signal increased as the amount of $\mathrm{NaCl}$ increase, reaching a maximum value and then decrease with further increase in salt concentration. Initially the analyte recovery is enhanced due to "salting-out" effect whereby water molecules form hydration spheres around the ionic salts molecules that reduce the concentration of water available to dissolve analyte molecules. This behaviour is felt especially for analytes with low hydrophobicity. By other hand the polar molecules may participate in electrostatic interactions with the salt ions in solution, thereby reducing their ability to move into

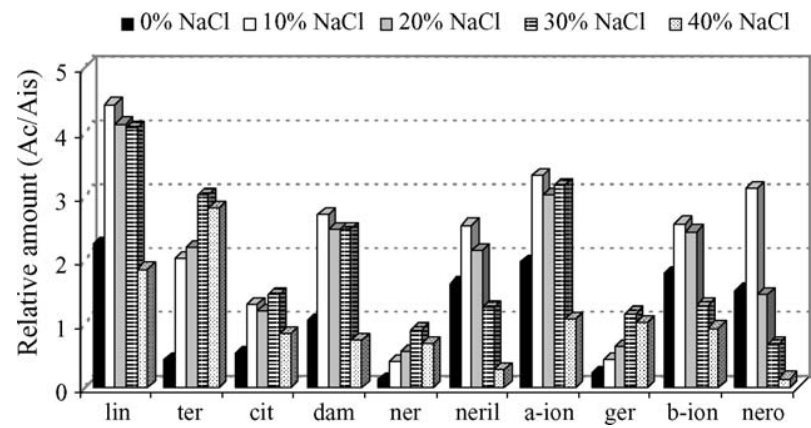

Fig. 5. Effect of salt $(\mathrm{NaCl})$ concentration on the extraction efficiency of flavour compounds in study in $18 \%$ ethanol solution, by dynamic headspace SPME using a PA $85 \mu \mathrm{m}$ fibre. The sample volume: $2.4 \mathrm{ml}$ (vial $4 \mathrm{ml}$ ); the SPME sampling temperature: $40^{\circ} \mathrm{C}$; the SPME sampling time: $120 \mathrm{~min}$; the desorption temperature: $260^{\circ} \mathrm{C}$; and the desorption time: $5 \mathrm{~min}$ (relative standard deviation range between $4.1 \%(\alpha$-ionone at $10 \% \mathrm{NaCl})$ and $14.3 \%($ nerol at $0 \% \mathrm{NaCl})$ ). 


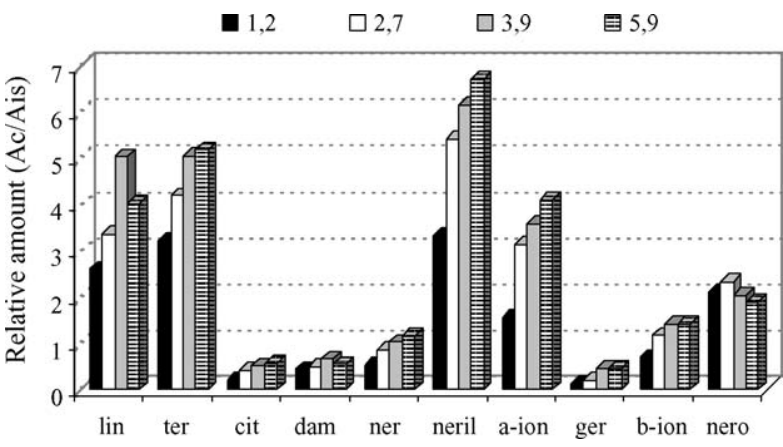

Fig. 6. Effect of $\mathrm{pH}$ on the extraction yield. The SPME sampling temperature: $40^{\circ} \mathrm{C}$; the SPME sampling time: $120 \mathrm{~min}$; the desorption temperature: $260{ }^{\circ} \mathrm{C}$; and the desorption time: 5 min (standard deviation ranging between 0.05 ( $\beta$ damascenone at $\mathrm{pH} 1.2$ ) and 0.6 (linalool at $\mathrm{pH}$ 3.9)).

the fibre coating. Finally, $30 \%$ of $\mathrm{NaCl}$ was added to all standards and samples in further experiments.

\subsubsection{Effect of $p H$}

A strong dependence of the extraction yield on the $\mathrm{pH}$ value is observed for the acidic and basic compounds. Such compounds may only be extracted quantitatively by SPME if they are present in the neutral form. The $\mathrm{pH}$ of the extraction mixture is particularly important for compounds possessing a $\mathrm{pH}$ dependent dissociable group. It is only the undissociated form that will be extracted by an absorptive type of fibre coating, like PA $85 \mu \mathrm{m}$.

To study the effect of $\mathrm{pH}$ on the extraction yield by SPME were prepared standard solutions of terpenoids at different $\mathrm{pH}$ values: 1.2, 2.7, 3.9 and 5.9. Fig. 6 shows the results obtained.

The results of ANOVA shows that there is no statistically significant differences for the different $\mathrm{pH}$ values studied, then all the experiments are performed with $\mathrm{pH}$ value (3.3-3.4) of real must and wine samples.

\subsubsection{Effect of ethanol content}

Because ethanol is one of the major constituents of wines, it will be taken into account for the other compounds extractability. Previous results in the literature describe the influence of the ethanol content on the efficiency of the SPME method [46].

For studying the possible effect of ethanol content on headspace SPME, solutions from three extractions were analysed for each of the four synthetic matrices with different ethanol contents $(0,5,12$ and $18 \%, v / v)$. Fig. 7 shows that a consistent decrease in the extraction yield was observed with increasing ethanol content for all the terpenoids studied. This decrease is greater for the most polar compounds-nerolidol, $\beta$-ionone, geraniol and $\alpha$-ionone. For linalool and $\beta$-terpineol the extraction yield is slightly influenced by the ethanol content.

This conclusion reveals the necessity of taking into account the percentage of ethanol in each wine analysed, in order to obtain the calibration curve with standards at the same ethanol content or correct the response for each compound studied.

\subsubsection{Desorption temperature and time}

The goal of optimising desorption process is typically to eliminate carryover and improve peak shape. A desorption time and

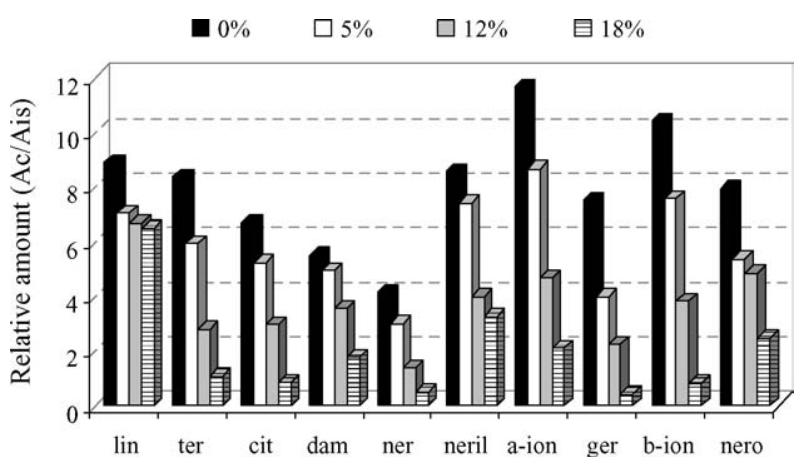

Fig. 7. Effect of the ethanol content in the efficiency extraction of flavour compounds by dynamic headspace SPME. The sample volume: $2.4 \mathrm{ml}$ (vial $4 \mathrm{ml}$ ); the SPME sampling temperature: $40^{\circ} \mathrm{C}$; the SPME sampling time: $120 \mathrm{~min}$; the desorption temperature: $260^{\circ} \mathrm{C}$; and the desorption time: $5 \mathrm{~min}$ (standard deviation range between 0.2 (nerol) and 1.2 ( $\beta$-ionone)).

temperature are selected such that any analyte remaining on the fibre after desorption will not cause variance in the results outside of normal method precision. The required desorption temperature may be close to the temperature of tolerance of the fibre coating, which may shorten the life of the fibre. Preliminary experiments showed that complete desorption was achieved for all the extracted analytes after 6 min of desorption at a temperature of $260^{\circ} \mathrm{C}$.

\subsection{Validation of the analytical method}

Having studied the optimised extraction parameters, calibration graphs using the internal standard method were built and the limits of detection and quantification of the method were estimated. All the experiments were carried out using the following analytical conditions: PA $85 \mu \mathrm{m}$ fibre with an extraction time of $60 \mathrm{~min}$ for musts and $120 \mathrm{~min}$ for wine samples, an extraction temperature of $40^{\circ} \mathrm{C}$, a sample volume of $2.4 \mathrm{ml}$ with a salt content of $30 \%$ and a constant stirring (1250 rpm). The analytes were desorbed for $6 \mathrm{~min}$ at $260^{\circ} \mathrm{C}$.

\subsubsection{Linearity and detection limits}

Three replicates of five standard solutions [water solution and $18 \%(\mathrm{v} / \mathrm{v})$ ethanol-water solution saturated with $\mathrm{NaCl}$ and $\mathrm{pH}$ adjusted at 3.3] in the range shown in Table 1, all of then with a content of internal standard of $0.422 \mu \mathrm{g} \mathrm{l}^{-1}$, were analysed. The mean values were used to construct the calibration graphs by plotting the peak area ratio against the standard concentration. Regression, slope and origin intercept (Table 1) were calculated by linear least-squares regression. Since the inverse of the slope is a measure of the response factor (RF) for each compound, the $\mathrm{RF}$ values for $\alpha$-ionone and $\beta$-ionone are very low contrary to linalool and nerol.

For most of the compounds studied, the resulting calibration curves obtained by plotting the GC-MS response versus analyte concentration were found to have good linearity in the tested concentration range, with $r^{2}$ values ranging between 0.977 and 0.999 for aqueous solution and between 0.985 and 0.999 for hydro alcoholic solution $(18 \%)$. 
Table 2

Limits of detection (LOD), limits of quantification (LOQ) and relative standard deviations (R.S.D.), of the analytical methodology developed (Aq. Sol.: aqueous solution, $\mathrm{pH}=3.3$ and $30 \% \mathrm{NaCl}$; EtOH $18 \%$ : ethanolic solution at $18 \%(\mathrm{v} / \mathrm{v}), \mathrm{pH}=3.3$ and $30 \% \mathrm{NaCl}$ )

\begin{tabular}{|c|c|c|c|c|c|c|}
\hline Terpenoids & \multicolumn{2}{|c|}{$\operatorname{LOD}\left(\mu g 1^{-1}\right)$} & \multicolumn{2}{|c|}{$\operatorname{LOQ}\left(\mu g 1^{-1}\right)$} & \multicolumn{2}{|c|}{ R.S.D. (\%) } \\
\hline Linalool & 2.02 & 3.02 & 3.62 & 10.06 & 5.09 & 5.61 \\
\hline Citronellol & 0.13 & 1.61 & 0.27 & 5.36 & 2.52 & 4.78 \\
\hline Nerol & 1.23 & 1.57 & 2.41 & 5.22 & 9.19 & 13.68 \\
\hline$\beta$-Damascenone & 0.84 & 0.42 & 1.23 & 1.41 & 8.50 & 12.09 \\
\hline Geraniol & 1.47 & 1.45 & 2.42 & 4.86 & 11.74 & 6.37 \\
\hline$\beta$-Ionone & 1.34 & 2.16 & 2.03 & 7.20 & 8.47 & 14.10 \\
\hline Nerolidol & 1.44 & 1.45 & 3.17 & 4.83 & 14.39 & 14.20 \\
\hline
\end{tabular}

The calculated LOD were found to be $0.13-2.95 \mu \mathrm{g} \mathrm{l^{-1 }}$ for aqueous solutions and $0.42-3.02 \mu \mathrm{g} 1^{-1}$ for hydro alcoholic solution $(18 \%, \mathrm{v} / \mathrm{v})$. Table 2 shows the estimated values of LOD and LOQ calculated under the described conditions. These are low enough to determine terpenoid compounds in real samples.

\subsubsection{Precision}

Under the conditions described above the intermediate precision, expressed by the relative standard deviation (R.S.D.) obtained on six independent analysis of the terpenoid standard solution range between $14.4 \%$ for nerolidol and $2.5 \%$ for citronellol (Table 2). For the $18 \%$ water-ethanol solution ( $\mathrm{pH} 3.3$ and $30 \%$ of $\mathrm{NaCl}$ ) the estimated values are similar $14.2 \%$ for nerolidol and $4.9 \%$ for citronellol.

For sample must the repeatability was $4.8 \%$ on average calculated from six replicates. The maximum values were near $10 \%$ for geraniol and the minimum was $0.4 \%$ for nerylcetone. For wine samples the repeatability was $8.3 \%$ on average with a maximum value of $22.2 \%$ for citronellol and the minimum of $2.0 \%$ for nerolidol. The results are presented in Table 3.

\subsubsection{Accuracy}

The recovery of the overall method was tested with a must and wine samples fortified with the analytes at two different levels (lower and higher concentration of the calibration graphs). Three samples of each were prepared and extracted according to the method described before. Table 3 shows the results for recoveries of each analyte. For must samples as can be seen, with exception of $\alpha$-terpineol (43.2\%) and $\beta$-ionone (11.1\%), the results shows a very good recovery $(71.9-117.9 \%)$ with a standard deviation less than $5 \%$. Wine samples, besides the higher standard deviation when compared with musts, also showed good recovery (74.7-124.4\%) except for nerolidol and nerol that have a recovery of 31.5 and $49.6 \%$, respectively.

Based on this data, the must and the wine matrices seem to have an effect on the headspace SPME procedure for the compounds studied. This problem can be reduced by using a standard addition calibration method or isotopically labelled internal standards.

\subsection{Application to real samples-must and Madeira wines}

After validation the analytical method was applied to a thirty six samples of must and the corresponding monovarietal wines from Boal, Malvazia, Sercial and Verdelho varieties to determine the terpenoid content. Each samples was analysed in triplicate. Both, identification by Kováts index and by mass spectrum of pure standards were used to identify the terpenoids in real sam-

Table 3

Average $(n=6)$ recoveries (\%) of terpenoid compounds in must and Madeira wine samples at two different levels

\begin{tabular}{|c|c|c|c|c|c|c|c|c|}
\hline \multirow[t]{3}{*}{ Terpenoids } & \multicolumn{4}{|l|}{ Level 1} & \multicolumn{4}{|l|}{ Level 2} \\
\hline & \multicolumn{2}{|l|}{ Must } & \multicolumn{2}{|l|}{ Wine } & \multicolumn{2}{|l|}{ Must } & \multicolumn{2}{|l|}{ Wine } \\
\hline & $\begin{array}{l}\text { Added } \\
\left(\mu g 1^{-1}\right)\end{array}$ & $\begin{array}{l}\text { Recovery } \\
(\%) \pm \text { R.S.D. }(\%)\end{array}$ & $\begin{array}{l}\text { Added } \\
\left(\mu g 1^{-1}\right)\end{array}$ & $\begin{array}{l}\text { Recovery } \\
(\%) \pm \text { R.S.D. }(\%)\end{array}$ & $\begin{array}{l}\text { Added } \\
\left(\mu g 1^{-1}\right)\end{array}$ & $\begin{array}{l}\text { Recovery } \\
(\%) \pm \text { R.S.D. }(\%)\end{array}$ & $\begin{array}{l}\text { Added } \\
\left(\mu g 1^{-1}\right)\end{array}$ & $\begin{array}{l}\text { Recovery } \\
(\%) \pm \text { R.S.D. }(\%)\end{array}$ \\
\hline Linalol & 8.6 & $86.4 \pm 4.0$ & 34.4 & $99.8 \pm 14.5$ & 43.0 & $89.5 \pm 3.7$ & 68.7 & $93.6 \pm 9.5$ \\
\hline$\alpha$-Terpineol & 4.6 & $43.2 \pm 5.4$ & 9.0 & $90.8 \pm 7.7$ & 23.0 & $48.4 \pm 6.3$ & 18.1 & $94.8 \pm 5.7$ \\
\hline Citronellol & 1.2 & $105.5 \pm 4.1$ & 6.6 & $102.5 \pm 22.2$ & 6.0 & $100.5 \pm 4.9$ & 19.2 & $97.5 \pm 14.2$ \\
\hline Nerylacetone & 3.5 & $76.6 \pm 1.9$ & 9.9 & $89.9 \pm 5.1$ & 17.5 & $73.4 \pm 3.8$ & 20.8 & $92.9 \pm 7.1$ \\
\hline$\alpha$-Ionone & 1.6 & $106.7 \pm 3.4$ & 8.2 & $115.9 \pm 6.5$ & 8.0 & $98.7 \pm 6.2$ & 12.4 & $105.9 \pm 9.2$ \\
\hline Geraniol & 2.9 & $98.5 \pm 8.7$ & 5.5 & $81.4 \pm 2.6$ & 14.5 & $94.7 \pm 5.7$ & 17.0 & $76.4 \pm 5.6$ \\
\hline$\beta$-Ionone & 3.8 & $11.1 \pm 4.6$ & 7.6 & $74.7 \pm 4.6$ & 19.0 & $13.1 \pm 6.7$ & 15.1 & $80.7 \pm 7.9$ \\
\hline Nerolidol & 1.8 & $103.5 \pm 0.2$ & 6.5 & $31.5 \pm 1.9$ & 9.0 & $97.3 \pm 2.9$ & 20.5 & $36.5 \pm 6.4$ \\
\hline
\end{tabular}


Table 4

Average $(n=3)$ concentrations $\left(\mu \mathrm{g}^{-1}\right)$ of dominating terpenoids found in musts of grape varieties under study determined by the developed method: HS-SPME using PA $85 \mu \mathrm{m}$ fibre (sample volume: $2.4 \mathrm{ml}$ (vial $4 \mathrm{ml}$ ); SPME sampling temperature: $40^{\circ} \mathrm{C}$; SPME sampling time: $60 \mathrm{~min}$; desorption temperature: $260^{\circ} \mathrm{C}$; desorption time: $5 \mathrm{~min})$

\begin{tabular}{|c|c|c|c|c|c|c|c|c|}
\hline \multirow[t]{2}{*}{ Terpenoids } & \multicolumn{2}{|l|}{ Boal } & \multicolumn{2}{|c|}{ Malvazia } & \multicolumn{2}{|l|}{ Sercial } & \multicolumn{2}{|c|}{ Verdelho } \\
\hline & Mean & R.S.D. \% & Mean & R.S.D. \% & Mean & R.S.D. \% & Mean & R.S.D. \% \\
\hline Linalol & 4.2 & 7.7 & 34.3 & 9.0 & 8.1 & 12.3 & 23.8 & 9.4 \\
\hline$\alpha$-Terpinol & 4.9 & 7.8 & 19.6 & 5.3 & 13.4 & 4.3 & 7.5 & 5.8 \\
\hline Citronellol & 0.5 & 11.9 & 0.3 & 7.6 & 0.8 & 10.4 & 0.5 & 6.1 \\
\hline Nerol & 3.8 & 5.7 & 2.9 & 3.1 & 1.3 & 11.9 & 3.8 & 3.3 \\
\hline$\beta$-Damascenone & 3.1 & 15.5 & 9.2 & 6.2 & 5.1 & 13.5 & 1.7 & 10.7 \\
\hline Geraniol & 2.9 & 15.2 & 4.7 & 10.9 & 6.4 & 10.7 & 2.7 & 11.5 \\
\hline$\beta$-Ionone & 4.4 & 5.3 & 2.1 & 5.2 & 8.3 & 7.6 & 4.7 & 8.7 \\
\hline Nerolidol & 53.1 & 8.4 & 37.4 & 11.8 & 21.0 & 5.8 & 16.2 & 10.2 \\
\hline
\end{tabular}

ples. The compounds quantified were chosen because they can be used for variety characterisation.

The average values for the free terpenoids determined in Boal, Malvazia, Sercial and Verdelho must and wine samples studied, from 2000 harvest, is shown in Table 4. The composition of free terpenoid fraction was different in the varieties studied.

For the year of study, the dominating terpenoids found in the analysed wines were linalool, $\alpha$-terpineol and $\beta$-damascenone. These compounds contribute to the flowery and pleasant, citrus and tropical fruit odours, respectively, of wines.

Wines derived from Malvazia grapes present the highest levels of terpenoids mainly due to the content of $\alpha$-terpineol and linalool, however these compounds are present at levels lower than its perception threshold. Contrary, Verdelho wines present the lowest concentrations of the free monoterpenols.

\section{Conclusions}

HS-SPME-GC-MS methodology was found to be fully suitable for the analysis of free monoterpenols and $\mathrm{C}_{13}$ norisoprenoids (terpenoids) in musts and wines, due to its selectivity and sensitivity. An optimised methodology was developed, which was based on $85 \mu \mathrm{m}$ PA fibre, headspace sampling mode and an extraction time of $60 \mathrm{~min}$ for musts and $120 \mathrm{~min}$ for wines at $40{ }^{\circ} \mathrm{C}$. The presence of electrolyte in the absorption system can changing the properties of the phase boundary and decreasing the solubility of the hydrophobic compounds in the aqueous phase increasing the sensitivity of the analytical method.

The quantification method used calibration curves obtained from standards extracted in the same experimental conditions as the samples, in order to account for the different extraction yields. The headspace method, in conjugation with GC-MS analysis, provides a high recovery, good linearity over a wide range of concentration and high sensitivity. Moreover, by optimising sampling methods, it was possible to obtain representative and reproducible HS-SPME extracts. Using only $2.4 \mathrm{ml}$ of sample, detection limits obtained are in low $\mu \mathrm{g}^{-1}$ range for all compounds examined in this study. This method offers a number of practical advantages: smaller sample volume, simplicity of extraction and low cost, when compared to other methods currently in use.
All these characteristics make the method useful for wine quality control, and to give information, which could be used, in the wine classification, in the control of wine origin and in winemaking processes.

\section{Acknowledgments}

We gratefully acknowledge to Instituto do Vinho da Madeira for the supply of wine samples, and PRODEP for financial support.

\section{References}

[1] A. Rapp, H. Mandery, Experientia 42 (1986) 873.

[2] S.P. Arrhenius, L. McCloskey, M. Sylvan, J. Agric. Food Chem. 44 (1996) 1085.

[3] P. Schreier, First Symposium in Vino Analytica Scientia; Ecole Européenne de Chimie Analytique, Bordeaux, France, 1997, p. 17, ISBN: 2-912526-00-0 (abstract book).

[4] R. Baumes, R. Cordonnier, S. Nitz, F. Drawert, J. Agric. Food Chem. 37 (1986) 927-934.

[5] A. Rapp, Fresen. J. Anal. Chem. 337 (1978) 777.

[6] K. Wada, T. Shibamoto, J. Agric. Food Chem. 45 (1997) 4362.

[7] A. Ferreira, A. Rapp, J. Cacho, H. Hastrich, I. Yavas, J. Agric. Food Chem. 41 (1993) 1413.

[8] P. Hardy, J. Agric. Food Chem. 17 (1969) 656.

[9] C. Ortega, R. López, J. Cacho, V. Ferreira, J. Chromatogr. A 923 (2001) 205.

[10] V. Ferreira, R. López, A. Escudero, J. Cacho, Chromatogr. A 806 (1998) 349.

[11] J.M. Nuñez, H. Bemelmans, J. Chromatogr. 294 (1984) 361.

[12] R. López, M. Aznar, J. Cacho, V. Ferreira, J. Chromatogr. A 966 (2002) 166.

[13] Y. Zhow, R. Riesen, C.S. Gilpin, J. Agric. Food Chem. 44 (1996) 818.

[14] S. Voirin, R. Baumes, J.C. Sapis, C. Bayonnove, J. Chromatogr. 595 (1992) 269

[15] Z. Gunata, C. Bayonnove, R. Baumes, R. Cordonnier, J. Chromatogr. 331 (1985) 83.

[16] P. Williams, C. Staruss, B. Wilson, R. Massy-Westropp, J. Chromatogr. 235 (1982) 471.

[17] G.P. Blanch, G. Reglero, M. Herraiz, J. Agric. Food Chem. 43 (1995) 1251.

[18] A. Razungles, H. Tarhi, R. Baumes, C. Gunata, C. Tapiero, C. Bayonnove, Sci. Alimments 14 (1994) 725.

[19] C. Cocito, G. Gaetano, C. Delfini, Food Chem. 52 (1995) 311.

[20] C. Arthur, J. Pawlizyn, Anal. Chem. 62 (1990) 2145.

[21] H.L. Lord, J. Pawlizyn, Anal. Chem. 69 (1997) 3899. 
[22] C. Arthur, L. Killam, K. Buchholz, J. Pawlizyn, J. Berg, Anal. Chem. 64 (1992) 1960

[23] D. De la Calle Garcia, S. Magnaghi, M. Reichenbacher, K. Danzer, J. High Resolut. Chromatogr. 19 (1996) 257.

[24] S.E. Ebeler, M.B. Terrien, C.E. Butzke, J. Sci. Food Chem. 80 (2000) 625.

[25] G. Vás, L. Gál, J. Harangi, A. Dobó, K. Vékey, J. Chromatogr. Sci. 36 (1998) 737.

[26] Jan C.R. Demyttenaere, C. Dagher, P. Sandra, S. Kallithraka, R. Verhé, N. De Kimpe, Chromatogr. A 985 (2003) 233.

[27] D. De la Calle Garcia, M. Reichenbacher, K. Danzer, C. Bartzch, K. Feller, J. High Resolut. Chromatogr. 22 (6) (1999) 322.

[28] D. De la Calle Garcia, S. Magnaghi, M. Reichenbacher, K. Danzer, Vitis 37 (1998) 181.

[29] D. De la Calle Garcia, S. Magnaghi, M. Reichenbacher, K. Danzer, J. High Resolut. Chromatogr. 21 (1998) 373.

[30] J.S. Câmara, P. Herbert, J.C. Marques, M.A. Alves, Anal. Chimica Acta 513 (2004) 203.

[31] J.J. Rodriguez-Bencomo, J.E. Conde, M.A. Rodriguez-Delgado, F. Garcia-Montelongo, J.P. Pérez-trujillo, J. Chromatogr. A 963 (2002) 213.

[32] M. Mestres, C. Sala, O. Busto, J. Guasch, J. Chromatogr. A 835 (1999) 137.

[33] M. Mestres, M.P. Marti, O. Busto, J. Guasch, J. Chromatogr. A 881 (2000) 583.
[34] M. Mestres, O. Busto, J. Guasch, J. Chromatogr. A 945 (2002) 211.

[35] A.P. Pollnitz, G.P. Jones, M.A. Sefton, J. Chromatogr. A 857 (1999) 239

[36] M. Correia, C. Delerue-Matos, A. Alves, J. Chromatogr. A 889 (2000) 59.

[37] C. Sala, M. Mestres, M.P. Marti, O. Busto, J. Guasch, J. Chromatogr. A 953 (2002) 41.

[38] L.M.T.V. Freire, A.M.C. Freitas, A.M. Relva, J. Microcol. Sep. 13 (2001) 236.

[39] E. Marengo, M. Aceto, V. Maurino, J. Chromatogr. A 943 (2002) 123.

[40] M.A. Pozo-Bayón, E. Pueyo, P.J. Martín-Álvarez, M.C. Polo, J. Chromatogr. A 922 (2001) 267.

[41] J.J. Rodriguez-Bencomo, J.E. Conde, F. Garcia-Montelongo, J.P. PérezTrujillo, J. Chromatogr. A 991 (2003) 13.

[42] T. Górecki, X. Yu, J. Pawliszyn, Analyst 124 (1999) 643.

[43] R.P. Schwarzenbach, P.M. Gschwend, D.M. Imboden, Environmental Organic Chemistry, John Wiley, New York, 1993, p. 225 (Chapter 11).

[44] R.I. Masel, Principles of Adsorption and Reaction on Solid Surfaces, John Wiley, New York, 1996.

[45] J.S. Câmara, A.M. Alves, J.C. Marques, Adv. Mass Spectrom. 15 (2001) 943.

[46] M. Correia, C. Delerue-Matos, A.M. Alves, J. Chromatogr. A 889 (2000) 59. 